\title{
An insight into the chemical composition of ground ivy (Glechoma hederacea L.) by means of macrocomponent analysis and fractionation of phenolic compounds
}

\author{
Danijela Šeremet, Aleksandra Vojvodić Cebin, Ana Mandura, Ivana Žepić, Ksenija Marković, Draženka Komes* \\ Faculty of Food Technology and Biotechnology, University of Zagreb, Pierottijeva 6, 10000 Zagreb, Croatia
}

*Corresponding author: dkomes@pbf.hr

\begin{abstract}
Ground ivy (Glechoma hederacea L.) has been used for generations in folk medicine to treat various diseases. Up until today, the information about its chemical and bioactive composition is still rather incomplete. The aim of this study was to evaluate macro-and microcomposition of ground ivy including the polyphenolic profile. In the present study, different phenolic fractions (free soluble, esterified, glycosylated and insoluble-bound phenolic fractions) of ground ivy were prepared and analysed using spectrophotometric methods (total phenolic content and antioxidant capacity) and HPLC-PAD methodology. Regarding the macrocomposition, the results revealed that most of the ground ivy dry matter was composed of insoluble dietary fibre $(48.96 \% \mathrm{dmb})$ followed by proteins $(17.92 \% \mathrm{dmb})$. Minerals also markedly contributed to the dry matter $(12.74 \% \mathrm{dmb})$ with potassium as the main macroelement $(48.49 \mathrm{mg} / \mathrm{g} \mathrm{dmb}$ ). Dominant phenolic compounds in ground ivy extract were: rosmarinic (6.64 $\mathrm{mg} / \mathrm{g}$ dmb) and chlorogenic acid $(1.11 \mathrm{mg} / \mathrm{g} \mathrm{dmb})$, and flavonol rutin $(1.87 \mathrm{mg} / \mathrm{g} \mathrm{dmb})$. Fractionation of phenolic compounds from ground ivy confirmed that dominant esters were indeed those of caffeic acid, while glycosides those of quercetin, which corresponded to the majority of identified compounds in the initial extract. Insoluble-bound phenolics were not represented in notable content. This study provided additional reference for macro- and microcomponent and phenolic composition of rather underutilized but valuable medicinal plant-ground ivy, to be used in further research of its health properties.
\end{abstract}

Keywords: HPLC, ground ivy (Glechoma hederacea L.), macro- and microcomposition, phenolic fractions, caffeic acid esters

\section{Introduction}

Plants have been used in different segments of life, such as medicine, nutrition, cosmetics, repellents, dyeing, etc. since ancient times (Sytar et al., 2016). They are extremely appreciated due to various positive effects on human health and are gaining attention in pharmaceutical research that is supported by the fact that some of the pharmaceutical lead molecules are plant-derived (Parasuraman, 2018). Phenolic compounds, as a group of secondary plant metabolites, are responsible for many biological effects of medicinal plants (Shahidi and Ambigaipalan, 2015). The most common phenolic compounds in plants are phenolic acids and flavonoids, but in nature they rarely occur in free forms. Phenolic acids are often present as insoluble or bound to macromolecules, while flavonoids often occur as glycosides (Acosta-Estrada et al., 2014). Most of the soluble phenolic compounds are situated in vacuoles of the plant cells, while the insoluble ones in the cell wall matrix where they are covalently bound to cell wall structural components (Shahidi and Yeo, 2016; Acosta-Estrada et al., 2014). Dietary intake of both free and bound phenolic compounds is beneficial for health, since free and soluble conjugated forms of phenolics will be absorbed in the stomach and small intestine, while most of the bound phenolics will be released during colonic fermentation (Acosta-Estrada et al., 2014; Zhang et al., 2012). The most common methods for releasing the phenolic compounds from their conjugated forms of esters and glycosides are alkaline and acidic hydrolysis, respectively. Alkaline hydrolysis is usually performed with sodium hydroxide (1-4 M) at room temperature with the addition of EDTA and ascorbic acid to prevent loss and degradation of phenolic compounds (Zhang et al., 2020; Acosta-Estrada et al., 2014). Acidic hydrolysis is often performed at elevated temperatures using aqueous and acidified organic solvents (Dzah et al., 2020). Glechoma hederacea L., of the Lamiaceae family, known as ground ivy, has been used for generations in folk medicine to treat various diseases (cold, asthma, diabetes, inflammations, etc.) (Chou et al., 2019), but still, there is lack of complete and scientifically-based information about its chemical and bioactive composition.

The aim of this study was to evaluate chemical composition of ground ivy by means of macrocomponents analysis (dietary fibre, protein and mineral content) and to obtain comprehensive information about its phenolic profile using the fractionation procedure for soluble and insoluble phenolics.

\section{Materials and methods}

\section{Materials and chemicals}

Ground ivy was bought from a local supplier (Zagreb, Croatia). Acetone and sodium sulphate (anhydrous) were purchased from Gram-mol d.o.o (Zagreb, Croatia) and sodium hydroxide and EDTA (ethylenediaminetetraacetic acid) from T.T.T d.o.o. (Sveta Nedelja, Croatia). Hydrochloric acid (37\%), bromcresol green and methyl red indicators, boric acid, L-ascorbic acid, (S)-6-Methoxy-2,5,7,8tetramethylchromane-2-carboxylic acid (Trolox), 2,2-Diphenyl-1picrylhydrazyl(DPPH), 2,2-Azino-bis(3 ethylbenzothiazoline-6-sulfonic acid) diammonium salt (ABTS), quercetin $(>97 \%)$, rutin trihydrate ( $>97 \%$ ), sinapic ( $>95 \%)$, rosmarinic $(97 \%)$, caffeic (HPLC standard) and chlorogenic acid (95\%) were purchased from Sigma-Aldrich (St. Louis, USA). Kjeldahl tablets were purchased from CarlRoth (Karsruhe, Germany) and an integrated total dietary fiber assay kit was purchased from Megazyme (Wicklow, Ireland). Methanol was supplied from Panreac (Barcelona, Spain), while sodium chloride, ethanol, n-hexane, formic acid, ethyl acetate and acetonitrile were purchased from Carlo 
Erba (Val de Reuil, France). All chemicals used for experimental procedures were of analytical or HPLC grade.

\section{Methods}

\section{Preparation of plant material}

Aerial parts of ground ivy were air-dried, grounded and sieved through a screen with pores of $450 \mu \mathrm{m}$, to obtain fractions $(<450 \mu \mathrm{m})$ to be used in further experiments.

\section{Characterization of macro- and microcomposition}

The dry matter, crude protein content, crude fat content and crude mineral content were determined according to the AOAC 930.15 (Padmore, 1990a), AOAC 976.05 (Padmore, 1990b), AOAC 920.39 (Padmore, 1990c) and AOAC 942.05 (Padmore, 1990d), respectively. The high molecular weight insoluble and soluble fiber content was determined using the Integrated Total Dietary Fiber Assay kit according to the AOAC 2011.25 method (McCleary et al., 2012). The content of microand macroelements was analysed using inductively coupled plasma mass spectrometer (Agilent 7500cx, Agilent Technologies, Tokyo, Japan).

\section{Extraction and fractionation of phenolic fractions}

Extraction and fractionation of phenolic compounds were performed according to the method of Arruda et al. (2018) with some modifications, yielding fractions of free soluble phenolics (FS PF), esterified conjugates (E PF), glycosylated conjugates (G PF) and insoluble-bound phenolics (I-B PF).

\section{a) Extraction of total soluble phenolic compounds}

The initial phenolic extract comprising totally extractable phenolics was prepared by mixing $0.5 \mathrm{~g}$ of ground ivy sample with $10 \mathrm{~mL}$ of a solvent mixture consisting of methanol/acetone/water $(7: 7: 6, \mathrm{v} / \mathrm{v} / \mathrm{v})$. The extraction was performed in an ultrasonic bath (Elmasonic 2120 , Elma, Singen, Germany; nominal power of $200 \mathrm{~W}$ and a frequency of $37 \mathrm{kHz}$ ), set to continuous working mode, for $15 \mathrm{~min}$ and followed by stirring on a magnetic stirrer (SMHS-6, Witeg, Wertheim, Germany) for additional $30 \mathrm{~min}$ at room temperature. Afterwards, the mixture was centrifuged at maximum speed for $10 \mathrm{~min}$ and the supernatant was collected. The residue was re-extracted 2 more times under the same conditions. The combined supernatants were evaporated under vacuum (IKA RV8, Staufen, Germany) to remove organic solvents and quantitatively transferred to a $5 \mathrm{~mL}$ volumetric flask. Such prepared extract was used in the fractionation protocol to distinguish between free soluble and conjugated (esterified and glycosylated) soluble phenolics. The extraction of total soluble phenolic compounds was performed in duplicate.

\section{b) Preparation of the free soluble phenolic fraction}

An aliquot of the evaporated extract was transferred to a glass screwcapped tube and acidified with $4 \mathrm{M} \mathrm{HCl}$ solution to reach $0.2 \mathrm{M}$ concentration. In addition, $\mathrm{NaCl}$ solution $(5 \mathrm{M})$ was added $(2 \mathrm{M}$ final concentration) to improve phase separation in the following steps. Free soluble phenolics were extracted by liquid-liquid extraction with ethyl acetate $(1: 1, \mathrm{v} / \mathrm{v})$ using vortex mixer for $1 \mathrm{~min}$. Phase separation after extraction was facilitated by brief centrifugation. The upper organic phase was transferred to a separate tube, while the aqueous phase was additionally extracted 2 more times, as described. The combined organic phases were dried by addition of a small amount of solid anhydrous sodium sulphate and quantitatively transferred into an evaporation flask. Ethyl acetate was completely evaporated under vacuum at $40{ }^{\circ} \mathrm{C}$. The dry residue was resuspended in a defined volume of $80 \%$ methanolic solution (equivalent to the volume of the aliquot of the evaporated extract) and filtered through syringe microfilters (RC, $0,2 \mu \mathrm{m})$ prior HPLC analysis. The fraction of free soluble phenolic compounds was prepared in duplicate.

\section{c) Preparation of the esterified phenolic fraction}

Soluble esterified phenolic conjugates were determined from the aqueous phase remained after the extraction of free soluble phenolic compounds by means of alkaline hydrolysis. Alkaline hydrolysis was performed with $2 \mathrm{M} \mathrm{NaOH}$ solution containing $10 \mathrm{mM}$ concentration of EDTA and $1 \%(\mathrm{w} / \mathrm{v})$ of ascorbic acid, for $2 \mathrm{~h}$ at room temperature. Afterwards, the extract was acidified to achieve neutralization of $\mathrm{NaOH}$ and further 0.2 $\mathrm{M} \mathrm{HCl}$ concentration. $\mathrm{NaCl}$ solution $(5 \mathrm{M})$ was added to adjust to final $\mathrm{NaCl}$ concentration of $2 \mathrm{M}$. The extraction of liberated phenolics was performed by liquid-liquid extraction with ethyl acetate, as described in previous section. The preparation of the fraction of soluble esterified phenolics was performed in duplicate.

\section{d) Preparation of the glycosylated phenolic fraction}

Soluble glycosylated phenolic conjugates were determined from the aqueous phase remained after the preparation of esterified phenolic fraction by means of acidic hydrolysis. Acidic hydrolysis was performed with $2 \mathrm{M} \mathrm{HCl}$ solution, for $1 \mathrm{~h}$ at $80^{\circ} \mathrm{C}$. Cooled hydrolysates were diluted with $\mathrm{NaCl}$ solution $(5 \mathrm{M})$ and water to reach $2 \mathrm{M} \mathrm{NaCl}$ concentration in a defined volume. The extraction of liberated phenolics was performed by liquid-liquid extraction with ethyl acetate, as described in previous section. The preparation of the fraction of soluble glycosylated phenolics was performed in duplicate.

\section{e) Preparing the insoluble-bound phenolic fraction by alkaline hydrolysis}

Insoluble-bound phenolic fraction was prepared by alkaline hydrolysis from the solid residue remained after initial extraction. The residue was washed twice with $5 \mathrm{~mL}$ of acetone and left under ventilation until acetone evaporated. The residue was quantitatively mixed with 2 $\mathrm{M} \mathrm{NaOH}$ solution containing EDTA $(10 \mathrm{mM})$ and ascorbic acid $(1 \%$, $\mathrm{w} / \mathrm{v})$, in ratio $(1: 10 \mathrm{w} / \mathrm{v})$ and extracted on a magnetic stirrer at room temperature for $2 \mathrm{~h}$. Afterwards, the mixture was acidified by slow addition $4 \mathrm{M} \mathrm{HCl}$ solution to achieve neutralization of $\mathrm{NaOH}$ and further $\mathrm{HCl}$ concentration of $0.2 \mathrm{M}$. In addition, $\mathrm{NaCl}$ solution $(5 \mathrm{M})$ was added to reach the final concentration of $2 \mathrm{M}$. The extraction of liberated phenolics was performed by liquid-liquid extraction with ethyl acetate, as described in previous section. The preparation of the fraction of insoluble-bound phenolics was performed in duplicate.

\section{Characterization of the initial extract and phenolic fractions}

\section{Determination of total phenolic content (TPC)}

Total phenolic content (TPC) of prepared extracts was determined spectrophotometrically (Genesys 10S UV-VIS Spectrophotometer, Thermo Fisher Scientific, US) using Folin-Ciocalteu reagent and following method described by Singleton and Rossi (1965). The standard calibration curve was constructed with solutions of gallic 
acid $(25-200 \mu \mathrm{g} / \mathrm{mL})$ and the results were expressed as mg gallic acid equivalents (GAE) per dry matter basis of the sample (mg GAE/g dmb). Measurements were performed in duplicate.

\section{Determination of antioxidant capacity}

The antioxidant capacity of extracts was determined using spectrophotometric (Genesys 10S UV-VIS Spectrophotometer, Thermo Fisher Scientific, USA) DPPH and ABTS radical cation decolourization assays according to the methods of Brand-Williams et al. (1995) and Re et al. (1999), respectively. Solutions of Trolox $(25-200 \mathrm{mmol} / \mathrm{mL})$ were used for the construction of the standard calibration curve and the results were expressed as mmol Trolox per dry matter basis of the sample (mmol Trolox/g dmb). Measurements were performed in duplicate.

\section{HPLC determination of individual phenolic compounds}

HPLC analysis was performed on Agilent Series 1200 chromatographic system (Agilent Technologies, Santa Clara, CA, USA) coupled with Photodiode Array Detector (PAD) (Agilent Technologies, Santa
Clara, CA, USA) and Zorbax Extend C18 (4.6 × $250 \mathrm{~mm}, 5 \mu \mathrm{m}$ i.d.) chromatographic column (Agilent Technologies, USA). The elution was performed in gradient with two-component mobile phase consisting of (A) $1 \%(\mathrm{v} / \mathrm{v})$ formic acid solution in water and (B) $1 \%(\mathrm{v} / \mathrm{v})$ formic acid solution in acetonitrile, according to the following regimen: $0 \mathrm{~min}$ - 93\% A, 7\% B; 5 min - 93\% A, 7\% B; 45 min - 60\% A, 40\% B; 47 $\min -30 \% \mathrm{~A}, 70 \% ; 52 \mathrm{~min}-30 \% \mathrm{~A}, 70 \% \mathrm{~B}$. The flow rate was $1 \mathrm{~mL} /$ min, the injection volume $5 \mu \mathrm{L}$ and the column temperature $25^{\circ} \mathrm{C}$. The chromatograms were recorded at 320,350 and $370 \mathrm{~nm}$. Identification of individual phenolic compounds was enabled by comparing the retention times and characteristic absorption spectra (190-400 nm) with commercially available standards. Quantification was enabled by establishing calibration curves for each identified compound $(20-100 \mu \mathrm{g} /$ $\mathrm{mL}$ ). The analysis was performed in duplicate. All samples were filtered through $0.2 \mu \mathrm{m}$ regenerated cellulose syringe filters (Macherey-Nagel. Germany) prior to analysis.

\section{Results and discussion \\ Macro- and microcomposition}

For the purpose of macrocomponent characterization (dietary fiber, protein, fat, ash) standard AOAC methods were used.

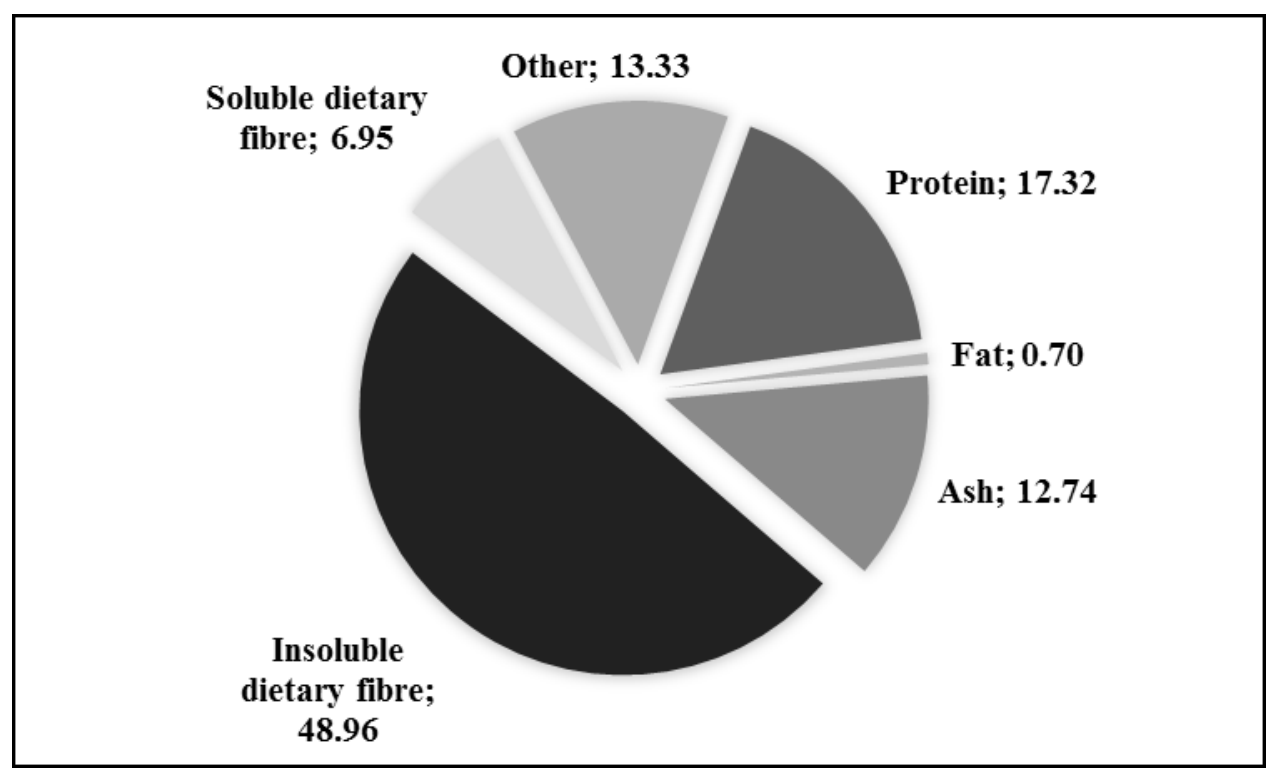

Figure 1. Macrocomponent composition (\% dmb*) of ground ivy *dmb-dry matter basis of the sample

As can be seen in Figure 1, almost half of the dry matter of ground ivy was composed of insoluble dietary fibre (48.96\%), which was expected and probably can be attributed to the high content of cellulose since cellulose makes around 50\% of all carbon found in plants (Barros et al., 2011). Soluble dietary fibre was represented by $6.95 \% \mathrm{dmb}$. Except for fiber, ground ivy was found to be relatively abundant also in proteins (17.32\% dmb) and minerals $(12.74 \% \mathrm{dmb})$. Fat content was negligible and made only $0.70 \%$ of the dry matter. According to its determined protein content, ground ivy is comparable with rich sources of proteins, namely, the grain legumes (24.0 - 26.1\%) (Iqbal et al., 2006). Due to the rather high content of minerals, the analysis of macro- and microelements in ground ivy was performed and the results are presented in Table 1. 
Table 1. Macro- and microelement content in ground ivy

\begin{tabular}{|c|c|c|c|c|c|}
\hline \multicolumn{6}{|c|}{ Macroelements (mg/kg dmb*) } \\
\hline $\mathrm{Na}$ & $M g$ & $K$ & $\mathrm{Ca}$ & $\mathrm{Fe}$ & $P$ \\
\hline $83.0 \pm 9.8$ & $3706.0 \pm 228.0$ & $48482.0 \pm 4370.0$ & $11648.0 \pm 1207.0$ & $249.0 \pm 35.6$ & $3415.0 \pm 290.0$ \\
\hline \multicolumn{6}{|c|}{ Microelements ( $\mu \mathrm{g} / \mathrm{kg} \mathrm{dmb})$} \\
\hline$V$ & $544.0 \pm 46.9$ & As & $117.0 \pm 8.4$ & $T I$ & $14.2 \pm 0.2$ \\
\hline$M n$ & $151.0 \pm 14.0$ & $\mathrm{Se}$ & $13.9 \pm 1.9$ & $\mathrm{~Pb}$ & $492.0 \pm 12.7$ \\
\hline $\mathrm{Cr}$ & $403.0 \pm 28.4$ & Mo & $382.0 \pm 16.9$ & $I$ & $528.0 \pm 34.6$ \\
\hline $\mathrm{Ni}$ & $1212.0 \pm 76.6$ & $C d$ & $101.0 \pm 2.0$ & $\mathrm{Cu}$ & $9.6 \pm 0.6$ \\
\hline$S b$ & $16.6 \pm 1.4$ & $S n$ & $28.2 \pm 2.4$ & $Z n$ & $65.0 \pm 4.2$ \\
\hline
\end{tabular}

*dmb-dry matter basis of the sample

Potassium was the main evaluated macroelement $(48.49 \mathrm{mg} / \mathrm{g} \mathrm{dmb})$, followed by calcium $(11.65 \mathrm{mg} / \mathrm{g} \mathrm{dmb})$ and magnesium and phosphorus, each in approximately 10-fold lower quantities (3.71 and $3.42 \mathrm{mg} / \mathrm{g} \mathrm{dmb}$, respectively). Among microelements, 15 elements were quantified, exhibiting Cu, $\mathrm{Se}$ and $\mathrm{Sb}$ as the least represented (9.6, 13.9 and $14.2 \mu \mathrm{g} / \mathrm{kg} \mathrm{dmb}$, respectively).

\section{Characterization of phenolic fractions}

Phenolic compounds in plant matrices can be found in free, conjugated or insoluble-bound form. For the purpose of more detailed characterization of the phenolic profile of ground ivy, fractionation was performed. Ground ivy extract and the prepared fractions of free soluble and conjugated soluble (esterified and glycosylated) as well as the fraction of insoluble-bound phenolic compounds, were analysed for TPC, antioxidant capacity and the content of individual phenolic compounds. TPC of the extract and prepared phenolic fractions is presented in Figure 2.

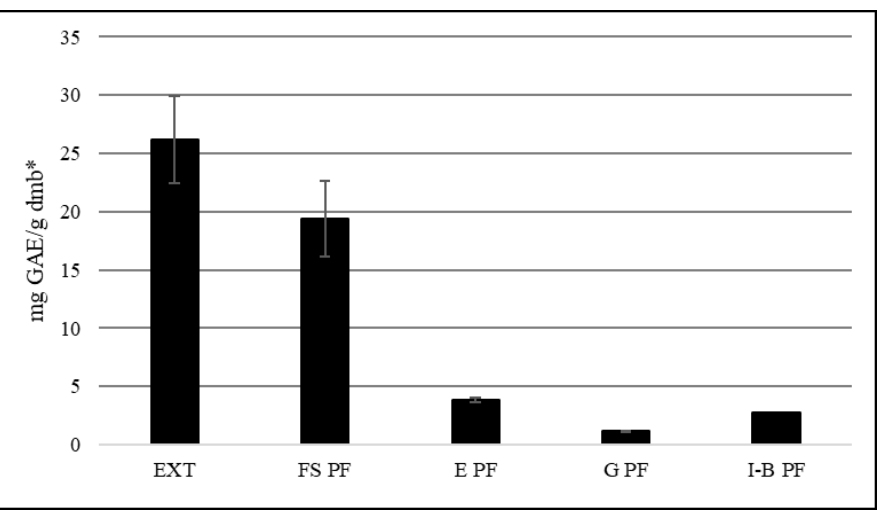

Figure 2. Total phenolic content (TPC) of extract (EXT) and prepared fractions (FS PF-free soluble phenolic fraction; $E P F$ - esterified phenolic fraction; $G P F-$ glycosylated phenolic fraction; $I-B P F-i n s o l u b l e-b o u n d ~ p h e n o l i c$ fraction)

*dmb-dry matter basis of the sample

TPC of the initial extract exhibited $26.22 \mathrm{mg} \mathrm{GAE} / \mathrm{g} \mathrm{dmb}$, followed by fractions of free soluble phenolic compounds (FS FC, $19.39 \mathrm{mg}$ GAE/g $\mathrm{dmb}$ ), esterified soluble phenolic compounds (E PF, $3.84 \mathrm{mg} \mathrm{GAE} / \mathrm{g}$ $\mathrm{dmb}$ ) and glycosidic form of phenolic conjugates (G PF, $1.20 \mathrm{mg}$ GAE/g $\mathrm{dmb}$ ). Despite the high contents of insoluble dietary fibre and proteins determined in ground ivy, insoluble-bound phenolic compounds were not indicated to be present in a significant amount $(2.73 \mathrm{mg} \mathrm{GAE} / \mathrm{g} \mathrm{dmb})$. Results of the evaluated antioxidant capacity using DPPH and ABTS radical scavenging assays are presented in Figure 3.

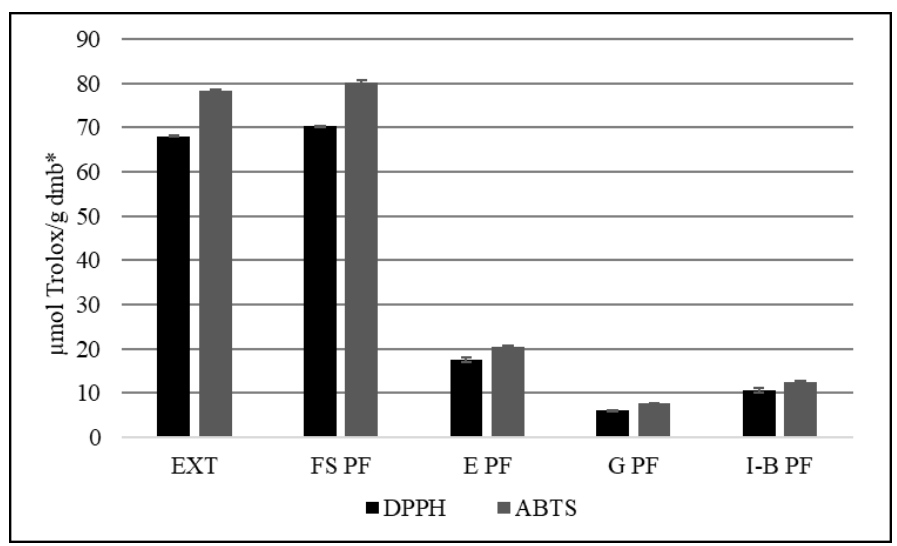

Figure 3. Antioxidant capacity (determined by DPPH and ABTS assay) of the initial extract (EXT) and the prepared fractions (FS PF-free soluble phenolic fraction; $E P F$ - esterified phenolic fraction; $G P F-$ glycosylated phenolic fraction; $I-B P F-$ insoluble-bound phenolic fraction) *dmb-dry matter basis of the sample

High correlations between TPC and DPPH-measured antioxidant activity $\left(\mathrm{R}^{2}=0.94\right)$ of the initial extract and the obtained fractions were observed, as well as for ABTS-measured antioxidant activity $\left(\mathrm{R}^{2}=0.95\right)$. The fraction of free soluble phenolic compounds exhibited the highest antioxidant capacity determined both by DPPH $(70.25 \mu \mathrm{mol}$ Trolox/g $\mathrm{dmb})$ and ABTS ( $80.15 \mu \mathrm{mol}$ Trolox/g dmb) assays, while glycosylated phenolic fraction the lowest (5.97 and $7.56 \mu \mathrm{mol}$ Trolox/g dmb, respectively).

In addition to TPC and antioxidant capacity measurements, the initial extract and phenolic fractions were characterized for individual phenolic compounds as well (Table 2). 
Table 2. Content ( $\mathrm{mg} / \mathrm{g} \mathrm{dmb}$ *) of individual phenolic compounds in extract and different phenolic fractions of ground ivy

\begin{tabular}{|c|c|c|c|c|c|c|}
\hline \multicolumn{2}{|l|}{} & $\begin{array}{c}\text { Total soluble } \\
\text { phenolic } \\
\text { compounds in } \\
\text { extract }\end{array}$ & $\begin{array}{c}\text { Fraction of free } \\
\text { soluble phenolic } \\
\text { compounds }\end{array}$ & $\begin{array}{c}\text { Esterified } \\
\text { phenolic } \\
\text { fraction }\end{array}$ & $\begin{array}{c}\text { Glycosylated } \\
\text { phenolic } \\
\text { fraction }\end{array}$ & $\begin{array}{c}\text { Insoluble-bound } \\
\text { phenolic fraction }\end{array}$ \\
\hline \multirow{5}{*}{ Phenolic acids } & Rosmarinic acid & $6.64 \pm 1.19$ & $5.39 \pm 1.31$ & - & - & \\
\cline { 2 - 8 } & Chlorogenic acid & $1.11 \pm 0.21$ & $0.90 \pm 0.13$ & - & - & - \\
\cline { 2 - 8 } & Caffeic acid & $0.25 \pm 0.05$ & $0.21 \pm 0.04$ & $0.09 \pm 0.01$ & - & $0.16 \pm 0.00$ \\
\cline { 2 - 8 } & Sinapic acid & - & - & $0.03 \pm 0.00$ & - & - \\
\hline \multirow{2}{*}{ Flavonoids } & Rutin & $1.87 \pm 0.35$ & $0.52 \pm 0.07$ & - & - & $0.06 \pm 0.01$ \\
\cline { 2 - 8 } & Quercetin & - & - & - & $0.02 \pm 0.00$ & - \\
\hline
\end{tabular}

*dmb-dry matter basis of the sample

Dominant phenolic compounds in the extract of ground ivy were hydroxycinnamic acids: rosmarinic acid (6.64 mg GAE/g dmb), chlorogenic acid (1.11 mg GAE/g dmb) and caffeic acid ( $0.25 \mathrm{mg} \mathrm{GAE} / \mathrm{g}$ $\mathrm{dmb})$, while among flavonoids, flavonol rutin (1.87 $\mathrm{mg} \mathrm{GAE} / \mathrm{g} \mathrm{dmb})$. A high content of rosmarinic acid is characteristic for the species of Lamiaceae family. Belščak-Cvitanović et al. (2014) also determined a high content of rosmarinic acid in ground ivy extract $(3.24 \mathrm{mg} / \mathrm{g} \mathrm{dmb})$. The content of rosmarinic, caffeic and chlorogenic acids in different parts of ground ivy was investigated by Döring and Petersen (2014) who reported the highest content of rosmarinic acid in the flower (12.53\%), then in the root $(1.31 \%)$, while significantly lower contents were quantified in leaves and stems -0.88 and $0.64 \%$, respectively. Further, the results of the present study are in accordance with the study by Chou et al. (2019) who also reported the presence of chlorogenic and caffeic acid in water extract of ground ivy, with rosmarinic acid as predominant $(13.98 \mathrm{mg} / \mathrm{g})$

Although esters of caffeic acid, rosmarinic and chlorogenic acids were easily extracted in the fraction of free soluble phenolics, both exhibiting recovery of approximately $81 \%$. At the same time, rutin exhibited recovery of approximately $28 \%$ in the fraction of free soluble phenolics, indicating that more complex phenolic glycosides are more retained in the aqueous phase during the fractionation procedure. In the fraction of esterified phenolics, caffeic and sinapic acids were determined (0.09 and $0.03 \mathrm{mg} / \mathrm{g} \mathrm{dmb}$, respectively). The presence of caffeic acid, at least the most part of it, was most probably due to the hydrolysis of the remaining rosmarinic and chlorogenic acids in the aqueous phase after the extraction of free soluble phenolics. The presence of sinapic acid, however, indicates the possibility of the presence of other ester-kind conjugates containing sinapic acid that were not originally determined in the initial extract due to the lack of standards. Although, their content is much lower that the dominating caffeic acid esters. In the fraction of glycosidic conjugates, quercetin was the only compound determined, deriving from the hydrolysis of rutin and indicating that rutin was the main, if not only phenolic glycoside determined in the initial extract. In the insoluble-bound phenolic fraction, only caffeic acid $(0.16 \mathrm{mg} / \mathrm{g}$ $\mathrm{dmb})$ and rutin $(0.06 \mathrm{mg} / \mathrm{g} \mathrm{dmb})$ were identified. From this standpoint it is not clear whether the observed bound phenolics are compounds that are genuinely bound or derived from residual non-extracted phenolics after the preparation of the initial extract. However, bound phenolics do not contribute significantly to the phenolics profile of ground ivy, i.e., soluble phenolic compounds are dominant in this medicinal plant.

\section{Conclusions}

This study provided valuable insight into the general and bioactive chemical composition of ground ivy (Glechoma hederacea L.) evaluated through macrocomponent and polyphenols analysis. High molecular weight insoluble fibre were dominant macrocomponent in the dry matter, followed by proteins and minerals, among which especially potassium and calcium. Phenolic compounds showed dominance in hydroxycinnamic acid derivatives, especially in caffeic acid esters such as rosmarinic and chlorogenic acids. Of flavonoids, only flavonol rutin was identified and further confirmed as quercetin derivative in the fraction of glycosylated phenolic fraction. Insoluble-bound phenolics, determined as caffeic acid and rutin, were not significantly present in ground ivy. The reported phenolics fractionation procedure was found to have limited suitability for ground ivy, as caffeic acid esters were easily extracted in the free soluble fraction, giving underestimation of esterified phenolics fraction. Ground ivy can be considered as a valuable source of bioactive natural compounds and minerals in the form of an extract, while implemented as a whole, in addition can contribute to the nutritional profile, especially in terms of dietary fibre.

\section{Acknowledgements}

This paper has been realized under the project: "Formulating encapsulated systems of bioactive ingredients from traditional plants: mountain germander and ground ivy for the development of innovative functional food products" (IP-2019-04-5879), funded by the Croatian Science Foundation.

\section{Reference}

Acosta-Estrada B.A., Gutiérrez-Uribe J.A., Serna-Saldívar S. (2014) Bound phenolics in foods, a review. Food Chemistry, 152 46-55.

Arruda H.S., Pereira G.A., de Morais D.R., Eberlin M.N., Pastore G.M. (2018) Determination of free, esterified, glycosylated and insoluble-bound phenolics composition in the edible part of araticum fruit (Annona crassiflora Mart.) and its by-products by HPLC-ESI-MS/MS. Food Chemistry, $245738-749$.

Barros L., Carvalho A.M., Ferreira C.F.R. (2011) From famine plants to tasty and fragrant spices: Three Lamiaceae of generaldietary relevance in traditional cuisine of Trás-os-Montes (Portugal). LWT-Food Science and Technology, 44 543-548. 
Belščak-Cvitanović A., Durgo K., Bušić A., Franekić J., Komes D. (2014) Phytochemical attributes of four conventionally extracted medicinal plants and cytotoxic evaluation of their extracts on human laryngeal carcinoma (Hep2) cells. Journal of Medicinal Food, 17 206-217.

Brand-Williams W., Cuvelier M. E., Berset C. (1995) Use of a free radical method to evaluate antioxidant activity. LWT - Food Science and Technology, 28 25-30.

Chou S.T., Lin T.H., Peng H.Y., Chao W.W. (2019) Phytochemical profile of hot water extract of Glechoma hederacea and its antioxidant, and antiinflammatory activities. Life Sciences, 231116519.

Döring A.S., Petersen M. (2014) Production of caffeic, chlorogenic and rosmarinic acids in plants and suspension cultures of Glechoma hederacea. Phytochemistry Letters, 718 1-7.

Dzah C.S., Duan Y., Zhang H., Boateng N.A.S., Ma H. (2020) Latest developments in polyphenol recovery and purification from plant by-products: A review. Trends in Food Science and Technology, 99 375-388.

Iqdal A., Khalil IA, Ateeq N, Khan MS (2006) Nutritional quality of important food legumes. Food Chemistry, 97 331-335.

McCleary B.V., DeVries J.W., Rader J.I., Cohen G., Prosky L., Mugford D.C., Okuma K. (2012) Determination of insoluble, soluble, and total dietary fibre (CODEX definition) by enzymatic-gravimetric method and liquid chromatography: Collaborative study. Journal of AOAC International, 95 824-844.

Padmore J.M. (1990a) Animal feed - AOAC official method 930.15 - Moisture in animal feed. In: Helrich K. (ed): Official Methods of Analysis, 15th ed., pp. 69-70. AOAC International, Arlington, VA, USA.

Padmore J.M. (1990b) Animal feed - AOAC official method 976.05 - Protein (crude) in animal feed, automated Kjeldahl method. In: Helrich K. (ed): Official Methods of Analysis, 15th ed., pp. 72. AOAC International, Arlington, VA, USA.

Padmore J.M. (1990c) Animal feed - AOAC official method 920.39 - Fat (crude) or ether extract in animal feed. In: Helrich K. (ed): Official Methods of Analysis, 15th ed., pp. 79. AOAC International, Arlington, VA, USA.

Padmore J.M. (1990d) Animal feed - AOAC official method 942.05-Ash of animal feed. In: Helrich K. (ed): Official Methods of Analysis, 15th ed., pp. 70. AOAC International, Arlington, VA, USA.

Parasuraman S. (2018) Herbal Drug Discovery: Challenges and Perspectives. Current Pharmacogenomics and Personalized Medicine, 16 (1) $63-68$. Re R., Pellegrini N., Proteggente A., Pannala A., Yang M., Rice-Evans C. (1999) Antioxidant activity applying an improved ABTS radical cation decolorisation assay. Free Radical Biology and Medicine, 26 1231-1237.

Shahidi F., Ambigaipalan P. (2015) Phenolics and polyphenolics in foods, beverages and spices: Antioxidant activity and health effects - A review. Journal of Functional Food, 18 820-897.

Singleton V.L., Rossi J.A. (1965) Colorimetry of total phenolics with phosphotungstic acid reagents. American Journal of Enology and Viticulture, $16144-158$.

Shahidi F., Yeo J.D. (2016) Insoluble-bound phenolics in food. Molecules, 211216.

Sytar O., Hemmerich I., Zivcak M., Rauh C., Brestic M. (2016) Comparative analysis of bioactive phenolic compounds composition from 26 medicinal plants. Saudi Journal of Biological Sciences, 25 (4) 631-641.

Zhang B., Zhang Y., Li H., Deng Z., Tsao R. (2010) A review on insoluble-bound phenolics in plant-based food matrix and their contribution to human health with future perspectives. Trends in Food Science \& Technology, 105 347-362.

Zhang X., Zhang M., Dong L., Jia X., Liu L., Ma Y., Huang F., Zhang R. (2019). Phytochemical profile, bioactivity, and prebiotic potential of bound phenolics released from rice bran dietary fiber during in vitro gastrointestinal digestion and colonic fermentation. Journal of Agricultural and Food Chemistry, 67 12796-12805. 